\title{
(6) OPEN ACCESS \\ Anabolic agents: recent strategies for their detection and protection from inadvertent doping
}

\author{
Hans Geyer, ${ }^{1,2}$ Wilhelm Schänzer, ${ }^{1}$ Mario Thevis ${ }^{1,2}$
}

\begin{abstract}
${ }^{1}$ Institute of Biochemistry, Center for Preventive Doping Research, German Sport University Cologne, Cologne, Germany

${ }^{2}$ European Monitoring Center for Emerging Doping Agents (EuMoCEDA), Cologne/Bonn, Germany
\end{abstract}

\section{Correspondence to} Dr Hans Geyer, Institute of Biochemistry, Center for Preventive Doping Research, German Sport University Cologne, Am Sportpark Müngersdorf 6, Cologne 50933, Germany; h.geyer@ biochem.dshs-koeln.de

Accepted 20 February 2014 Published Online First 14 March 2014
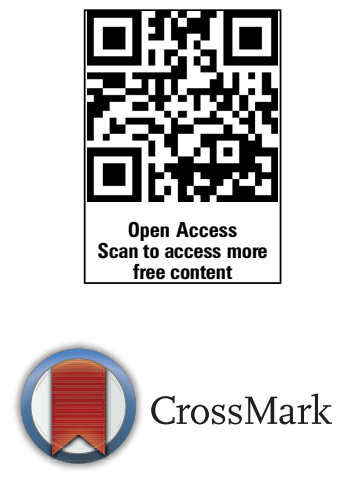

To cite: Geyer $\mathrm{H}$, Schänzer W, Thevis M. Br J Sports Med 2014:48: 820-826.

\section{ABSTRACT}

According to the World Anti-Doping Agency (WADA) Prohibited List, anabolic agents consist of exogenous anabolic androgenic steroids (AAS), endogenous AAS and other anabolic agents such as clenbuterol and selective androgen receptor modulators (SARMs). Currently employed strategies for their improved detection include the prolongation of the detection windows for exogenous AAS, non-targeted and indirect analytical approaches for the detection of modified steroids (designer steroids), the athlete's biological passport and isotope ratio mass spectrometry for the detection of the misuse of endogenous AAS, as well as preventive doping research for the detection of SARMs. The recent use of these strategies led to 4-80-fold increases of adverse analytical findings for exogenous AAS, to the detection of the misuse of new designer steroids, to adverse analytical findings of different endogenous AAS and to the first adverse analytical findings of SARMs. The strategies of the antidoping research are not only focused on the development of methods to catch the cheating athlete but also to protect the clean athlete from inadvertent doping. Within the past few years several sources of inadvertent doping with anabolic agents have been identified. Among these are nutritional supplements adulterated with AAS, meat products contaminated with clenbuterol, mycotoxin (zearalenone) contamination leading to zeranol findings, and natural products containing endogenous AAS. The protection strategy consists of further investigations in case of reasonable suspicion of inadvertent doping, publication of the results, education of athletes and development of methods to differentiate between intentional and unintentional doping.

\section{INTRODUCTION}

Since years anabolic agents are the most frequently detected doping substances in sports. This is also valid for 2012. Of 4500 adverse analytical and atypical findings reported by the World Anti-Doping Agency (WADA) accredited laboratories via the Anti-Doping Administration and Management System (ADAMS), about 50\% are anabolic agents ${ }^{1}$ (figure 1). Anabolic agents are detected in all sports ${ }^{1}$ and they are mainly misused because of their anabolic effects such as muscle growth, increase of strength, accelerated recovery and anticatabolic effects under strenuous exercise.

According to the WADA Prohibited List, anabolic agents consist of exogenous anabolic androgenic steroids (AAS) including for instance stanozolol, metandienone, oxandrolone, etc, endogenous AAS such as testosterone, dehydroepiandrosterone, androstenedione, etc and other anabolic agents such as clenbuterol and selective androgen receptor modulators (SARMs). ${ }^{2}$

Analytical challenges for the detection of the misuse of anabolic agents result from various different facts, among which a few are of major concern. These include the growing problem of the administration of unapproved and/or new designer substances, the evidently increasing use of endogenous substances, the constantly decreasing concentrations of the analytes detected in positive doping control samples (most probably due to the use of microdoses or to an earlier cessation of the drug regimen before doping controls are expected), and genetic polymorphisms that lead to different metabolic patterns in the tested individuals. Besides, major problems in connection with anabolic agents arise from 'doping traps', which can lead to inadvertent doping cases. Candidates for such traps are, for example, nutritional supplements adulterated with endogenous or exogenous AAS, food contaminated with clenbuterol and animal tissues used in traditional medicine therapeutics that contain endogenous AAS, etc. Here, the challenge obviously is to identify such sources of inadvertent doping to be able to warn and protect athletes.

Recent strategies to manage such challenges in connection with anabolic agents are presented.

\section{Prolongation of the detection window for exogenous AAS}

The detection of exogenous AAS is commonly based on the detection of their urinary phase-I and phase-II metabolites. Owing to the long lasting effects of AAS on athletic performance, the recent strategy of antidoping research is mainly focused on the search for long-term metabolites (LTMs) of exogenous AAS. The implementation of LTMs into the analytical screening procedures allows the prolongation of the detection window and an increased retrospectivity for AAS. In 1996 the first publications focused on LTMs of exogenous AAS were published. ${ }^{3} 4$

The prolongation of the detection windows is not only due to the implementation of their LTMs into sports drug testing but also to the use of highly sensitive detection methods employing chromatographic/mass spectrometric techniques (eg, LC-MS/MS, GC-MS/MS, HRMS) in screening procedures. The most recent methods, which combine LTMs and new sophisticated mass spectrometric methods are compiled in table 1 . These strategies of exploiting new analytical technologies and alternative target compounds have led to an enormous increase of adverse analytical findings (AAFs) in the past. For instance, the implementation of the LTM for metandienone (18-nor-17 $\beta$-hydroxymethyl, 
Figure 1 Adverse analytical findings and atypical findings of all World Anti-Doping Agency (WADA) accredited laboratories in 2012 reported via Anti-Doping Administration and Management System (ADAMS). ${ }^{1}$

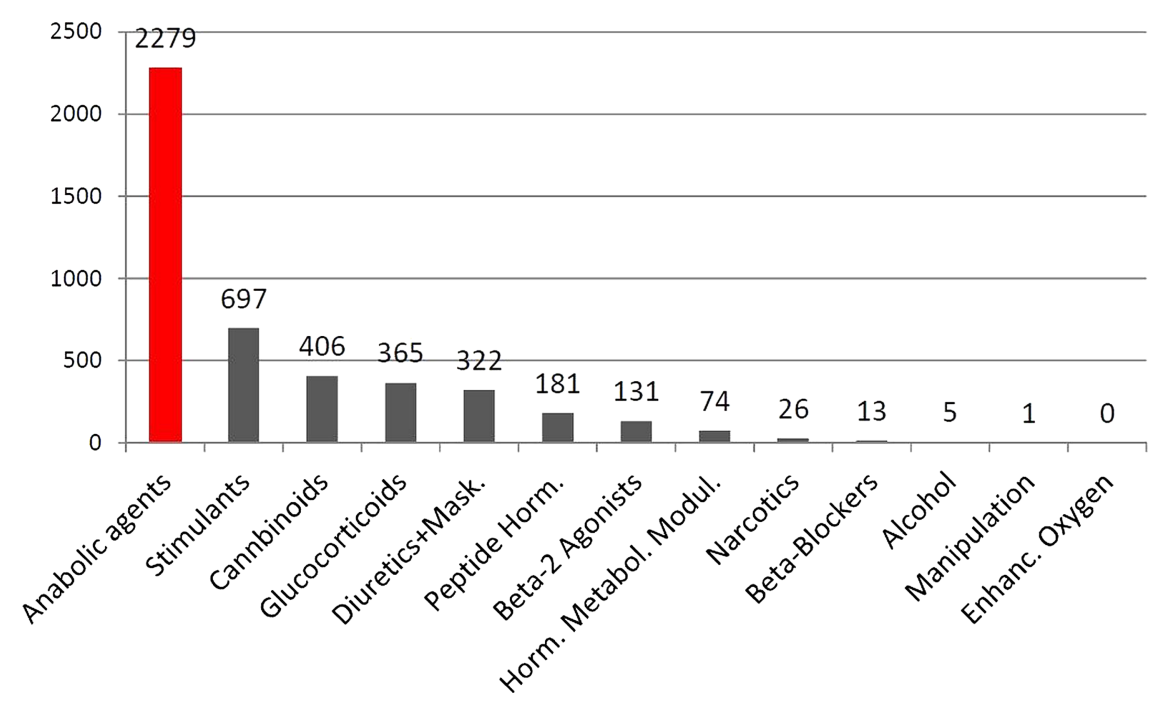

$17 \alpha$-methyl-androst-1,4,13-trien-3-one) in the screening procedure of the WADA accredited laboratory Cologne in 2006 resulted in an increase of AAFs with metandienone of more than $400 \%$ from approximately $12-15$ AAFs in the years 20032005 to 68 AAFs in 2006, although the number and origin of the analysed samples was nearly constant (figure 2). As Cologne was the first WADA accredited laboratory in the world to screen for this new metabolite, the number of AAFs for metandienone in Cologne in 2006 was higher than the sum of AAFs for metandienone of all other WADA accredited laboratories. ${ }^{5}$ This effect of the implementation of new LTMs was even more pronounced with regard to the detection of AAFs for dehydrochloromethyltestosterone. In January 2013, three new LTMs for dehydrochloromethyltestosterone were implemented in the screening procedures of the Cologne laboratory (see table 1). This led to an increase of AAFs from an annual average number of 1-82 cases in the first 11 months of 2013 (figure 3). Only one or two of these 82 cases would have been detected with the methods used till the end of 2012 in the Cologne laboratory.

Another substantial increment in the number of AAFs was observed for the exogenous AAS stanozolol, also resulting from expanding the detection window for some of its metabolites (see table 1). Here, the use of high-resolution/high-accuracy mass spectrometry was considered decisive, which allowed for the detection of the stanozolol metabolite $3^{\prime}$-hydroxystanozolol-O-glucuronide in initial test methods at concentrations as low as $20 \mathrm{pg} / \mathrm{mL}$; moreover, a pattern of other established as well as new stanozolol metabolites corroborated the findings, which included stanozolol$\mathrm{N}$-glucuronide, stanozolol-O-glucuronide, 16ß-hydroxystanozolol$O$-glucuronide, and 4 $\beta$-hydroxystanozolol-glucuronide and the new LTM 17-epistanozolol-N-glucuronide. This screening method was implemented at the beginning of December 2012 in the Cologne laboratory and led to an increase of AAFs for stanozolol from an annual average of about 23 cases to 182 cases from early

Table 1 Recent methods for the prolonged detection of exogenous AAS by the combination of the implementation of LTMs in screening procedures and the use of sensitive mass spectrometric methods

\begin{tabular}{|c|c|c|}
\hline Exogenous AAS & LTMs & References \\
\hline Metandienone & 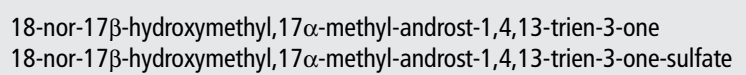 & $10,59,60$ \\
\hline Oxandrolone & $\begin{array}{l}17 \beta \text {-hydroxymethyl-17 } \alpha \text {-methyl-18-nor-2-oxa-5 } \alpha \text {-androsta-13-en-3-one } \\
17 \alpha \text {-hydroxymethyl-17 } \beta \text {-methyl-18-nor-2-oxa-5 } \alpha \text {-androsta-13-en-3-one }\end{array}$ & 61 \\
\hline Oxymetholone & 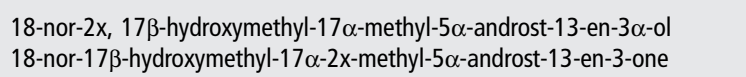 & 7 \\
\hline Desoxymethyltestosterone & 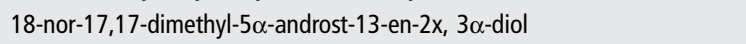 & 7 \\
\hline Dehydrochloromethyltestosterone & $\begin{array}{l}\text { 4-chloro-17-methyl-5 } \beta \text {-androstane-3,16,17-triol } \\
\text { 4-chloro-17-hydroxymethyl-17-methyl-18-nor-5 } \beta \text {-androst-1,13-diene-3-ol } \\
\text { 4-chloro-17-hydroxymethyl-17-methyl-18-nor-5 } \beta \text {-androst-13-ene-3-ol }\end{array}$ & 6 \\
\hline Stanozolol & $\begin{array}{l}\text { Stanozolol- } N \text {-glucuronide } \\
\text { Stanozolol-O-glucuronide } \\
\text { Epistanozolol- } N \text {-glucuronide } \\
3^{\prime} \text {-Hydroxystanozolol-O-glucuronide } \\
16 \beta \text {-Hydroxystanozolol- } O \text {-glucuronide } \\
4 \beta \text {-Hydroxystanozolol-O-glucuronide }\end{array}$ & 24 \\
\hline
\end{tabular}




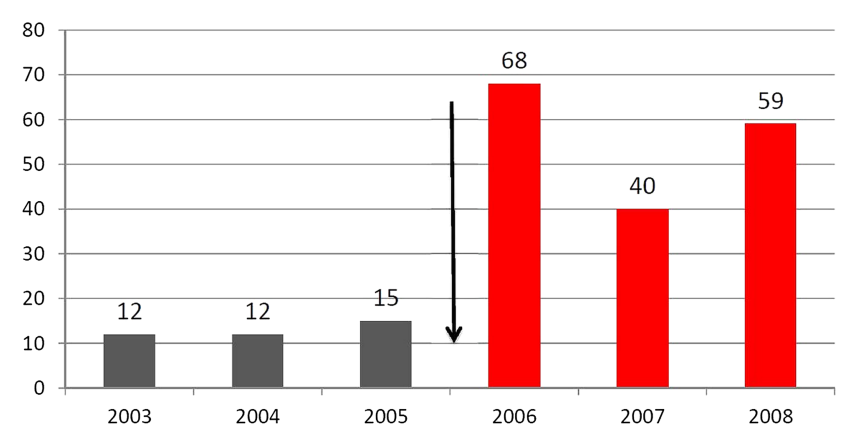

Figure 2 Adverse analytical findings for metandienone in the World Anti-Doping Agency (WADA) accredited laboratory Cologne before and after the prolongation of the detection window for metandienone by the implementation of a new long-term metabolite in the screening procedure in January 2006.

December 2012 until beginning December 2013 (figure 4). About $90 \%$ of the stanozolol cases would not have been detected in the Cologne laboratory with the previous methods.

The identification of LTMs of different anabolic steroids was accomplished by means of several different methodologies including fractionation and in-depth elucidation of urine samples collected from human administration studies ${ }^{6}{ }^{7}$ and animal model elimination studies. ${ }^{8} 9$ A novel approach was recently presented, which is based on the administration of deuterated steroids followed by the identification of the respective deuterated urinary metabolites using hydrogen isotope ratio mass spectrometry. ${ }^{10}$ Owing to the enormous specificity and sensitivity of the MS analyser for deuterated substances (requiring as little as $0.5 \mathrm{ng} / \mathrm{mL}$ of analyte), urine samples are readily measured for target compounds showing prolonged elimination times and, thus, might support expanded detection windows and retrospectivity.

\section{Non-targeted and indirect analytical approaches for the detection of modified steroids (designer steroids)}

'Tailored' steroidal agents with assumed (or proven) anabolic-androgenic properties have become a predominant issue for doping control laboratories since the early 2000s. Commonly referred to as 'designer steroids', these compounds are not approved therapeutics and, largely, have also not undergone clinical trials. One of the first designer steroids, detected in a nutritional supplement, was $3 \beta$-hydroxyandrost4-ene-7,17-dione. ${ }^{11}$ The most public attention however was received by the substance tetrahydrogestrinone (THG), which

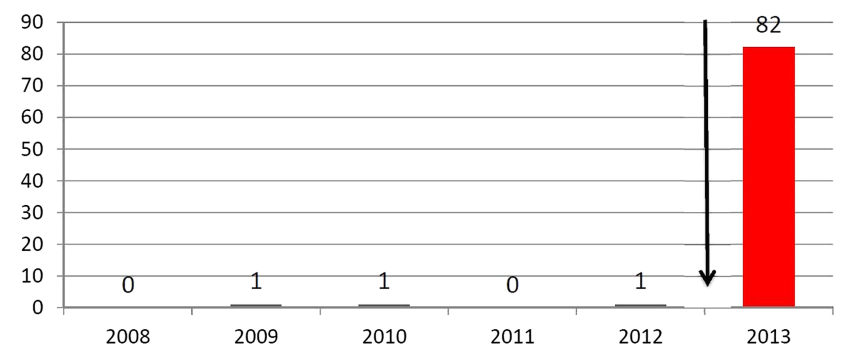

Figure 3 Adverse analytical findings for dehydrochloromethyltestosterone in the World Anti-Doping Agency (WADA) accredited laboratory Cologne before and after the prolongation of the detection window for dehydrochloromethyltestosterone by the implementation of three new long-term metabolites in December 2012 in the screening procedure (status from 1 December 2013).

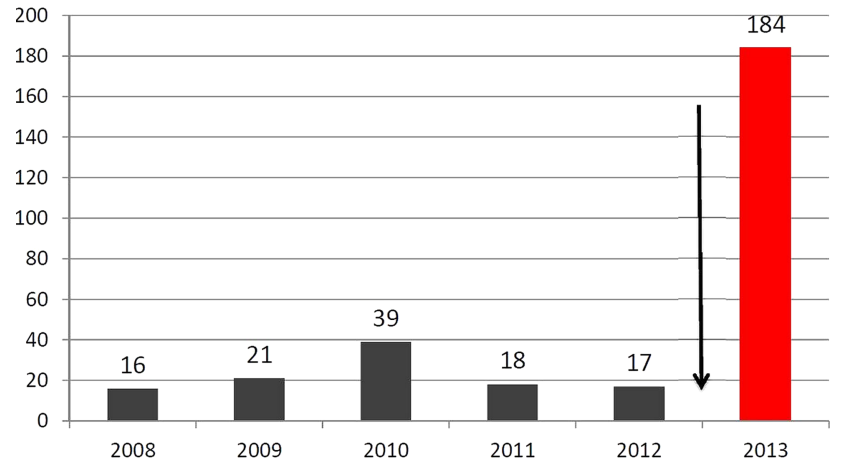

Figure 4 Adverse analytical findings for stanozolol in the World Anti-Doping Agency (WADA) accredited laboratory Cologne before and after the prolongation of the detection window for stanozolol by the use of high-resolution mass spectrometry in combination with the implementation of old and new stanozolol metabolites and a new long-term metabolite in December 2012 (status from 1 December 2013).

was detected in connection with the BALCO case in 2003 and identified by the WADA-accredited laboratory in Los Angeles. ${ }^{12}$ From 2002 until 2008 a total of 22 steroidal compounds, arguably modified to remain undetected in doping controls, were identified by WADA-accredited laboratories ${ }^{13}$ and the need to complement target-oriented analytical methods as usually employed in routine sports drug testing by non-targeted approaches had become evident. Consequently, strategies to combat the purported as well as proven abuse of designer steroids have been evaluated, two of which were particularly promising: the non-targeted approach focusing on the detection of characteristic and common fragment/product ions derived from conserved nuclei of AAS, and the indirect approach based on monitoring the biological effect of AAS on the profile of endogenous steroids.

\section{Non-targeted approach}

Naturally occurring endogenous androgens are well defined and known from the basis of thousands of annual doping control samples worldwide. Hence, a viable approach towards uncovering the presence of derivatives of testosterone and its synthetic analogues has been the screening for commonalities of steroidal agents by means of mass spectrometry and to flag those peaks that are not normally seen in doping control samples. Triggered by the aforementioned BALCO scandal and the identified THG, studies concerning a substantial variety of known AAS were conducted. As illustrated in figure $5,{ }^{14}{ }^{15}$ this approach allowed for the identification of structure-specific product ions such as $\mathrm{m} / \mathrm{z}$ 241 of gestrinone and its derivatives. In addition, testosterone derivatives frequently yield A/B-ring specific product ions at $\mathrm{m} / \mathrm{z}$ 97 and $109,{ }^{16-18}$ trenbolone analogues result in abundant product ions at $\mathrm{m} / \mathrm{z} 227,{ }^{19}$ and other specifics allow to generally detect and characterise structural features of subgroups of AAS. $^{20} 21$ Employing LC-MS/MS in precursor ion scan mode, diagnostic product ions (such as the aforementioned species) can lead to respective precursor ions and support the detection of designer variants of established doping agents. This approach was successfully applied to routine doping controls enabling the revealing of the misuse of the trenbolone analogue methyltrienolone (methyltrenbolone) in 2008, resulting in the detection and subsequent identification of the drug in 11 weightlifters before the Olympic Games in Beijing. ${ }^{22}$ Further studies on generic dissociation patterns of steroidal agents were conducted, suggesting the use of product ions obtained through higher 
Figure 5 Non-targeted analysis (precursor ion scan): screening for a common fragment of different steroids $(\mathrm{m} / \mathrm{z} 241)$.

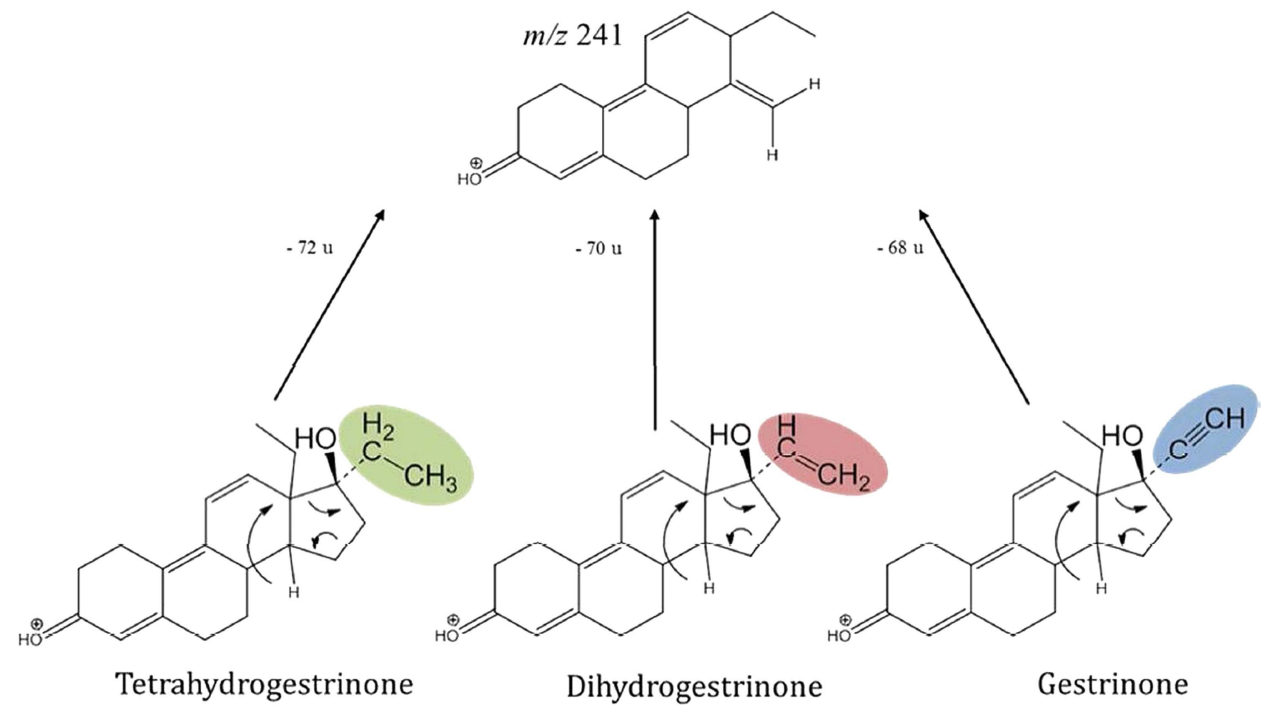

energy collision-induced dissociation, for example, $\mathrm{m} / \mathrm{z}$ 77, 91 and $105,{ }^{23}$ which can indicate in a similar fashion steroidal core structures in LC-MS/MS analyses. Since these strategies are not dedicated to single analytes, groups of steroid-derived doping agents are covered and more comprehensive analyses are possible. The price to pay for comprehensiveness, however, is the methods' sensitivity. While targeted analyses for selected steroids allow for detection limits as low as $5 \mathrm{pg} / \mathrm{mL},{ }^{24}$ non-targeted approaches have to compromise sensitivity and typically higher detection limits of screening protocols at approximately $10-20 \mathrm{ng} / \mathrm{mL}$.

\section{Indirect approach}

The indirect approach for the detection of designer steroids is based on endocrinological feedback mechanisms and the effect of these steroids on the profile of urinary endogenous steroids (steroid profile), which is monitored for each athlete within the Athlete's Biological Passport (ABP, vide infra). It is well known that the administration of AAS leads to a suppression of the excretion of endogenous steroids. ${ }^{25} 26$ Therefore, suppressed endogenous steroid concentrations may trigger a search for unknown designer steroids. This strategy was successfully applied in the detection of the misuse of norbolethone in $2002,{ }^{27}$ where unusual steroid profiles suggested the misuse of a yet unknown (or at least not screened) AAS. However, the determination of arguably steroid abuse-influenced urinary steroid profiles does not allow for reporting an AAF. The administered drug still needs to be identified; nevertheless, the suspicion resulting from steroid profile analyses is of great importance in target testing of athletes and further investigations of the collected doping control urine samples.

\section{The ABP approach and isotope ratio mass spectrometry for the detection of the misuse of endogenous AAS}

For approximately 30 years the misuse of endogenous AAS is detected via alterations in the urinary steroid profile. ${ }^{28}$ The main parameters of the steroid profile as analysed in doping control laboratories are the concentrations and ratios of the glucuronidated testosterone metabolites androsterone, aetiocholanolone, $5 \alpha$-androstane- $3 \alpha, 17 \beta$-diol and $5 \beta$-androstane- $3 \alpha$, $17 \beta$-diol as well as the glucuronidated epitestosterone, which originates from the biosynthesis of testosterone. Among these parameters the best elucidated and investigated item is the ratio of testosterone and epitestosterone (T/E) which was introduced in doping controls by Donike et $a l^{29}$ to provide a means to detect the misuse of testosterone. The administration of testosterone and other endogenous steroids leads to 'abnormal' steroid profiles, for example, abnormally increased $\mathrm{T} / \mathrm{E}$ ratios. The first strategies to differentiate between normal and abnormal steroid profiles were based on population-based reference limits. With the growing knowledge of individuals with naturally abnormal steroid profiles, for example, naturally increased or decreased $\mathrm{T} / \mathrm{E}$ ratios, the strategy changed from the use of population-based evaluation towards individual reference ranges. ${ }^{30}$ The establishment of individual reference ranges was first adopted by UCI in the mid-1990s to identify individuals with naturally elevated $\mathrm{T} / \mathrm{E}$ ratios to prevent false-positive cases. This was carried out by means of so-called endocrinological studies. $^{31}$ The combination of the application of populationbased and individual reference ranges led to one of the biggest doping scandals in the mid 1990s when during the Asian Games 1994 in Hiroshima, Japan, nine gold medallists were sanctioned for doping with the endogenous AAS dihydrotestosterone. ${ }^{32}$

To globalise this strategy, that is, to be able to compare steroid profiles analysed at different locations, WADA and the accredited doping control laboratories harmonised the employed analytical methods. Additionally the ADAMS was further developed to enable combining the collected steroid profiles of all doping control samples and the direct comparison with individual and population based reference ranges. The calculation of the individual reference ranges is performed on the basis of an adaptive model developed by Sottas et al. ${ }^{33} 34$

All these elements are now adopted in the steroidal module of the ABP approach. Together with the increasing knowledge about factors influencing the steroid profile, for example, pharmaceutical, genetic, pathological, analytical, medical and other aspects, ${ }^{35}$ this strategy has proven fit-for-purpose to support detecting the misuse of endogenous AAS. The steroidal $\mathrm{ABP}$ is an open system and additional urinary steroids and ratios can be used for the decision-making process. ${ }^{35-37}$ An invaluable addition to this strategy is the use of the isotope ratio mass spectrometry (IRMS). This technique allows to differentiate between natural and synthetic endogenous steroids by means of the ratios of the stable carbon isotopes ${ }^{13} \mathrm{C}$ and ${ }^{12} \mathrm{C},{ }^{38}{ }^{39}$ that is, a suspicion of the misuse of endogenous AAS, triggered by the steroidal module of the ABP, can be proven by subsequent IRMS analyses. 


\section{Preventive doping research approach for the detection of SARMs}

Being categorised as 'other anabolic agents', SARMs have been prohibited according to WADA's regulations since 2008. Owing to their proven anabolic properties and ability to stimulate the androgen receptor in muscle and bone, a substantial misuse potential was identified. This might be even more fuelled by the fact that SARMs inhibit androgen receptor activity in other organs (eg, skin and prostate) and have demonstrated less (or at least other) undesirable effects on the human organism than AAS.

Numerous SARMs have been subjected to preclinical and clinical trials since the first non-steroidal representatives of this new class of therapeutics were introduced in $1998 .{ }^{40}$ The number of new drug (or chemical) entities with SARM-like properties has been growing constantly and reviews on recent developments are frequently published ${ }^{41}$; however, full clinical approval has not been accomplished for any of the drug candidate SARMs yet, although the arylpropionamide-derived therapeutic Ostarine (figure 6B) has been in phase-III clinical trials and might be launched for specific interventions in the near future. In fact, numerous potential candidates were discontinued, arguably due to inacceptable side effects. A selection of 10 SARM substances is depicted in figure 6, illustrating the chemical heterogeneity and thus the analytical challenge for sports drug testing laboratories for these emerging compounds.

Although not yet marketed, SARMs are prohibited and their therapeutic profile has certainly justified the proactive method development for detecting these analytes as comprehensive as possible in routine doping controls. As such, SARMs have been a matter of preventive doping research, and first assays allowing for the analysis of arylpropionamide-derived SARMs (such as Andarine and Ostarine) were published in $2006 .{ }^{42}$ In the subsequent years, a great variety of additional though structurally different SARM candidates were presented in scientific articles as well as patents. Representatives of these were studied concerning their traceability in sports drug testing samples including blood and urine, ${ }^{43}{ }^{44}$ largely requiring their chemical synthesis due to limited/non-availability of reference material. Moreover, their metabolism was investigated using in vitro or animal in vivo models to provide potential target analytes for efficient urine doping controls. ${ }^{45}$ The relevance of the work was demonstrated soon after as SARM drug candidates including the officially discontinued Andarine were offered and sold by Internet-based suppliers, ${ }^{46}{ }^{47}$ and first AAFs with Andarine were reported in $2010^{48}$ and $2011 .^{49}$ These findings highlight the importance of preventive doping research and the options given to antidoping authorities to reduce cheating athletes' windows of opportunity to abuse yet non-approved drugs. It is however a task of substantial complexity and benefits greatly from constructive collaborations with partners in the pharmaceutical industry, at European (EuMoCEDA) and international (WADA) level.

\section{Protection of athletes from inadvertent doping with anabolic agents}

Within the past few years, several sources of inadvertent doping with anabolic agents have been identified. Among these are nutritional supplements adulterated with AAS, meat products contaminated with clenbuterol and natural products containing endogenous AAS.

Since about 2003 a great number of nutritional supplements have become available, advertised with claims of enormous muscle growth and increase in strength. According to the advertisements and the labels these biological effects are attributed to new ingredients and formulae with fantasy-derived and unapproved names. The analyses of many of these products has shown that they contain exogenous AAS such as metandienone,<smiles>CC(=O)Nc1ccc(OC[C@@](C)(O)C(=O)Nc2ccc([N+](=O)[O-])c(C(F)(F)F)c2)cc1</smiles>

G<smiles>CN(C)C1CC(C(C)(C)CO)Nc2ccc([N+](=O)[O-])cc21</smiles>

I
H<smiles>CC(C)(CO)C1Nc2ccc([N+](=O)[O-])cc2C2C=CCC21</smiles><smiles>Cc1ccc(-c2nnc([C@H](Nc3ccc(C#N)c(Cl)c3C)C(C)(O)O)o2)cc1</smiles>

$\mathbf{J}$<smiles>Cc1c(N2C3CCCC2CC(C)(O)C3)ccc(C#N)c1Cl</smiles>

Figure 6 Chemical structures of selected selective androgen receptor modulator drug candidates: andarine (A), ostarine (B), BMS-564929 (C), 4-(7-hydroxy-1,3-dioxo-tetrahydro-pyrrolo[1,2-c]imidazol-2-yl)-naphthalene-1-carbonitrile (D), LGD-121071 (E), LGD-2226 (F), S-40503 (G), 2-methyl-2-(8-nitro-3a,4,5,9b-tetrahydro-3H-cyclopenta[c]chinolin-4-yl)propan-1-ol (H), RAD140 (I), and ACP-105 (J). 
Figure 7 Steroids detected in a musk pod sample. ${ }^{59}$

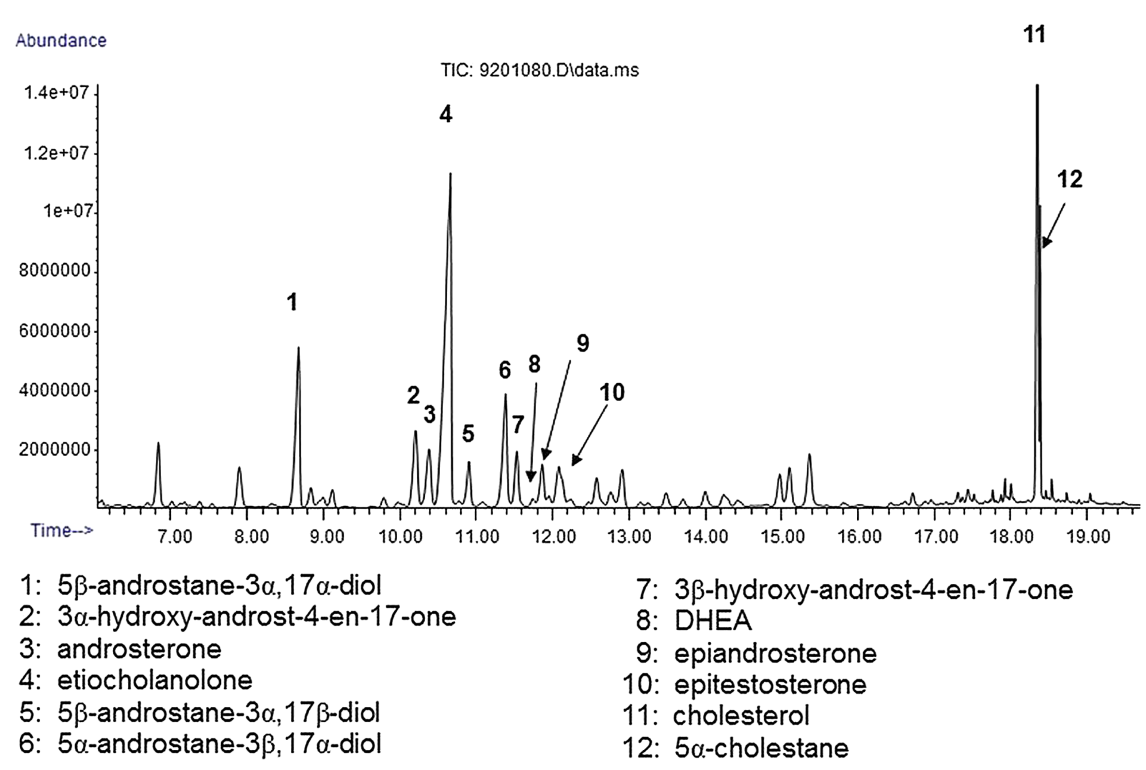

stanozolol, oxandrolone and dehydrochloromethyltestosterone in therapeutic or even supratherapeutic doses, not declared on the label. Also nutritional supplements adulterated with clenbuterol have been detected, which were additionally advertised with their fat burning effects. ${ }^{13}{ }^{50}$ The consumption of such supplements inevitably leads to AAFs and is connected with considerable health risks. Criminal nutritional supplement producers use this strategy to establish their ineffective products in the sports market. To prevent inadvertent doping cases athletes should avoid the consumption of nutritional supplements, which are advertised with extreme claims of muscle growth, increase of strength and fat loss. ${ }^{51}$ The best strategy to overcome this problem seems to be the appropriate education of athletes.

A further source of inadvertent doping, which attracted attention within the past 3 years was meat contaminated with clenbuterol. The anabolic agent clenbuterol has been evidently misused as growth promoter in cattle feeding in selected countries and meat originating from these farms can contain traces of clenbuterol leading to AAFs or even poisonings. In 2010 and 2011 unexplainable doping cases with clenbuterol of groups of athletes in table tennis and soccer led to investigations of the origin of these findings. It could be shown that the travel and stay in China and Mexico was connected with a high risk of inadvertent doping with clenbuterol. ${ }^{52} 53$ The most probable source is contaminated meat but other animal products such as milk or offal cannot be excluded. Also other risk countries might exist. The antidoping research, which also includes investigations to protect athletes from inadvertent doping, is now focused on the development of methods to differentiate between clenbuterol originating from medication and from contaminated meat. Promising results are provided by studies of pharmacokinetics and metabolism of clenbuterol. ${ }^{54}$ A further tool for the differentiation of inadvertent and intentional ingestion of doping agents maybe hair analysis. ${ }^{56}$

Similar to the clenbuterol contamination issue, the unintentional intake of the mycotoxin zearalenone can result in AAFs concerning one of its human urinary metabolites referred to as zeranol. Zeranol has been prohibited according to the regulations of WADA as an anabolic agent and its formation from zearalenone has been observed in humans, representing an analytical challenge for doping controls as the drug's deliberate intake needs to be differentiated from the consumption of mycotoxin-contaminated produce. A viable strategy was established employing metabolite profiling of zearalenone and zeranol in case of suspicious test results, which confirmed zearalenone as the origin of zeranol findings in 2011.57

A very unusual source of arguably inadvertent doping with anabolic agents was detected during the FIFA women's World Cup 2011 in soccer in Germany. ${ }^{58}$ Five players of a team were tested positive for endogenous AAS. The AAFs were detected by means of atypical steroid profiles and confirmed by positive IRMS results. Extracts and grains of deer musk pods were identified as source of the positive results. These animal products contained huge amounts of 16 different endogenous AAS of which 9 were listed on the WADA Prohibited List 2011 (see figure 7). These musk deer products were claimed to be used by the team to increase mental strength without knowing that the consumption leads to AAFs.

These examples show that antidoping research is not only focused on the development of methods to catch the cheating athlete but also to protect the clean athlete. The protection strategy consists of the following steps: further investigations in case of reasonable suspicion of inadvertent doping, publication of the results, education of athletes, development of methods to differentiate between intentional and inadvertent doping.

\section{Important aspects of this review are}

- Anabolic agents remain the most frequently detected class of doping agents in elite sport.

- A significant increase in findings has been observed whenever new target analytes for improved retrospectivity were introduced.

- New, emerging therapeutics of non-steroidal structure have entered the illicit market and have been detected recently in sports drug testing.

- Analytical strategies largely rely on steroid profiling and target analyte detection with continuously improving detection windows. 
Contributors HG, WS and MT contributed equally to the different review chapters with literature review, data compiling and preparation of the manuscript.

Competing interests None.

Patient consent Obtained.

Provenance and peer review Not commissioned; externally peer reviewed.

Open Access This is an Open Access article distributed in accordance with the Creative Commons Attribution Non Commercial (CC BY-NC 3.0) license, which permits others to distribute, remix, adapt, build upon this work non-commercially, and license their derivative works on different terms, provided the original work is properly cited and the use is non-commercial. See: http://creativecommons.org/ licenses/by-nc/3.0/

\section{REFERENCES}

1 WADA. 2012 Anti-Doping Testing Figures Report. World Anti-Doping Agency, 2013.

2 WADA. The 2014 prohibited list. Montreal: World Anti-Doping Agency, 2014.

3 Schänzer $W$, Delahaut $P$, Geyer $H$, et al. Long-term detection and identification of metandienone and stanozolol abuse in athletes by gas chromatography-highresolution mass spectrometry. J Chromatogr B 1996;687:93-108.

4 Schänzer W, Horning S, Opfermann G, et al. Gas chromatography/mass spectrometry identification of long-term excreted metabolites of the anabolic steroid 4-chloro-1,2-dehydro-17alpha-methyltestosterone in humans. J Steroid Biochem Mol Biol 1996;57:363-76.

5 Fußhöller G, Mareck U, Schmechel A, et al. Long-term detection of metandienone abuse by means of the new metabolite 17B-hydroxymethyl-17 $\alpha$-methyl-18norandrost-1,4,13-trien-3-one. In: Schänzer W, Geyer H, Gotzmann A, Mareck U. eds Recent advances in doping analysis. Cologne: Sportverlag Strauss, 2007:15:393-6.

6 Sobolevsky T, Rodchenkov G. Detection and mass spectrometric characterization of novel long-term dehydrochloromethyltestosterone metabolites in human urine. J Steroid Biochem Molec Biol 2012;128:121-7.

7 Sobolevsky T, Rodchenkov G. Mass spectrometric description of novel oxymetholone and desoxymethyltestosterone metabolites identified in human urine and their importance for doping control. Drug Test Anal 2012;4:682-91.

8 Lootens L, Meuleman P, Pozo OJ, et al. uPA+/+-SCID mouse with humanized liver as a model for in vivo metabolism of exogenous steroids: methandienone as a case study. Clin Chem 2009;55:1783-93.

9 Lootens L, Van Eenoo P, Meuleman P, et al. Steroid metabolism in chimeric mice with humanized liver. Drug Test Anal 2009:1:531-7.

10 Thevis $\mathrm{M}$, Piper $\mathrm{T}$, Horning $\mathrm{S}$, et al. Hydrogen isotope ratio mass spectrometry and high-resolution/high-accuracy mass spectrometry in metabolite identification studies: detecting target compounds for sports drug testing. Rapid Commun Mass Spectrom 2013;27:1904-12.

11 Delbeke FT, Van Eenoo P, Van Thuyne W, et al. Prohormones and sport. I Steroid Biochem Molec Biol 2002;83:245-51.

12 Catlin DH, Sekera MH, Ahrens BD, et al. Tetrahydrogestrinone: discovery, synthesis, and detection in urine. Rapid Commun Mass Spectrom 2004;18:1245-9.

13 Geyer H, Parr MK, Koehler K, et al. Nutritional supplements cross-contaminated and faked with doping substances. J Mass Spectrom 2008;43:892-902.

14 Thevis $\mathrm{M}$, Geyer $\mathrm{H}$, Mareck U, et al. Screening for unknown synthetic steroids in human urine by liquid chromatography-tandem mass spectrometry. J Mass Spectrom 2005; 40:955-62

15 Thevis M, Opfermann G, Bommerich U, et al. Characterization of chemically modified steroids for doping control purposes by electrospray ionization tandem mass spectrometry. J Mass Spectrom 2005;40:494-502.

16 Williams TM, Kind AJ, Houghton E, et al. Electrospray collision-induced dissociation of testosterone and testosterone hydroxy analogs. J Mass Spectrom 1999;34:206-16.

17 Pozo OJ, Van Eenoo P, Deventer K, et al. Collision-induced dissociation of 3-keto anabolic steroids and related compounds after electrospray ionization. Considerations for structural elucidation. Rapid Commun Mass Spectrom 2008:22:409-24.

18 Thevis M, Beuck S, Höppner S, et al. Structure elucidation of the diagnostic product ion at $\mathrm{m} / \mathrm{z} 97$ derived from androst-4-en-3-one-based steroids by ESI-CID and IRMPD spectroscopy. J Am Soc Mass Spectrom 2012;23:537-46.

19 Thevis M, Guddat S, Schänzer W. Doping control analysis of trenbolone and related compounds using liquid chromatography-tandem mass spectrometry. Steroids 2009:74:315-21.

20 Thevis M, Schänzer W. Mass spectrometric analysis of androstan-17beta-ol-3-one and androstadiene-17beta-0l-3-one isomers. J Am Soc Mass Spectrom 2005;16:1660-9.

21 Thevis $\mathrm{M}$, Schänzer W. Mass spectrometry in sports drug testing: structure characterization and analytical assays. Mass Spectrom Rev 2007;26:79-107.

22 AAP. Greek weightlifters banned from Beijing Olympics. Perth now. Perth: Australian Associated Press, 2008.
23 Pozo OJ, Deventer K, Eenoo PV, et al. Efficient approach for the comprehensive detection of unknown anabolic steroids and metabolites in human urine by liquid chromatography-electrospray-tandem mass spectrometry. Anal Chem 2008;80:1709-20

24 Schänzer W, Guddat S, Thomas A, et al. Expanding analytical possibilities concerning the detection of stanozolol misuse by means of high resolution/high accuracy mass spectrometric detection of stanozolol glucuronides in human sports drug testing. Drug Test Anal 2013;5:810-18.

25 Donike $\mathrm{M}$, Geyer $\mathrm{H}$, Schänzer W, et al. Die Suppression der endogenen Androgenproduktion durch Metandienon. In: Franz I-W, Mellerowicz H, Noack W. eds Training und Sport zur Prävention und Rehabilitation in der technisierten Umwelt. Berlin, Heiderlberg, New York: Springer Verlag, 1985:508.

26 Donike $\mathrm{M}$, Geyer $\mathrm{H}$, Kraft $\mathrm{M}$, et al. Longterm influence of anabolic steroid misuse on the steroid profile, in Official Proceedings of the IInd I.A.F. Belotti P, Benzi G, Ljungqvist A.eds World symposium on doping in sport. Monte Carlo: International Athletic Foundation, 1989:107-16.

27 Catlin DH, Ahrens BD, Kucherova Y. Detection of norbolethone, an anabolic steroid never marketed, in athleteś urine. Rapid Commun Mass Spectrom 2002:16:1273-5.

28 Donike M, Bärwald KR, Klostermann K, et al. The detection of exogenous testosterone. In: Heck H, Hollmann W, Liesen H.eds Leistung und Gesundheit, Kongressbd, Dtsch. Sportärztekongress. Köln: Deutscher Ärtze-Verlag, 1983:293-8.

29 Donike M, Zimmermann J, Bärwald KR, et al. Routinebestimmung von Anabolika in Harn. Dtsch Z Sportmed 1984;35:14-24.

30 Donike M, Rauth S, Mareck-Engelke U, et al. Evaluation of longitudinal studies: the determination of subject-based reference ranges of the testosterone/epitestosterone ratio. In: Geyer H, Gotzmann A, Mareck-Engelke U, Rauth S.eds Recent advances in doping analysis. Cologne: Sport\&Buch Strauss, 1993:33-9.

31 Geyer $H$, Mareck U, Schänzer W, et al. The Cologne protocol to follow up high testosterone/epitestosterone ratios. In: Schänzer W, Geyer H, Gotzmann A, Mareck U.eds Recent advances in doping analysis. Cologne: Sport und Buch Strauss, 1997:4:107-26.

32 Donike M, Ueki M, Kuroda Y, et al. Detection of dihydrotestosterone (DHT) doping: alterations in the steroid profile and reference ranges for DHT and its 5 alphametabolites. J Sports Med Phys Fitness 1995;35:235-50.

33 Sottas PE, Saugy M, Saudan C. Endogenous steroid profiling in the athlete biological passport. Endocrinol Metab Clinics North Am 2010;39:59-73, viii-ix.

34 Sottas PE, Baume N, Saudan C, et al. Bayesian detection of abnormal values in longitudinal biomarkers with an application to T/E ratio. Biostatistics 2007:8:285-96.

35 Mareck $\mathrm{U}$, Geyer $\mathrm{H}$, Opfermann $\mathrm{G}$, et al. Factors influencing the steroid profile in doping control analysis. J Mass Spectrom 2008;43:877-91.

36 Van Renterghem P, Van Eenoo P, Van Thuyne W, et al. Validation of an extended method for the detection of the misuse of endogenous steroids in sports, including new hydroxylated metabolites. J Chromatogr B 2008:876:225-35.

37 Van Renterghem P, Van Eenoo P, Geyer $H$, et al. Reference ranges for urinary concentrations and ratios of endogenous steroids, which can be used as markers for steroid misuse, in a Caucasian population of athletes. Steroids 2010;75:154-63.

38 Piper T, Emery C, Saugy M. Recent developments in the use of isotope ratio mass spectrometry in sports drug testing. Anal Bioanal Chem 2011;401:433-47.

39 Becchi M, Aguilera R, Farizon Y, et al. Gas chromatography/combustion/ isotope-ratio mass spectrometry analysis of urinary steroids to detect misuse of testosterone in sport. Rapid Commun Mass Spectrom 1994;8:304-8.

40 Dalton JT, Mukherjee A, Zhu Z, et al. Discovery of nonsteroidal androgens. Biochem Biophys Res Commun 1998;244:1-4.

41 Dalton JT, Taylor RP, Mohler ML, et al. Selective androgen receptor modulators for the prevention and treatment of muscle wasting associated with cancer. Curr Opin Support Palliat Care 2013;7:345-51.

42 Thevis $M$, Kamber $M$, Schänzer W. Screening for metabolically stable aryl-propionamide-derived selective androgen receptor modulators for doping contro purposes. Rapid Commun Mass Spectrom 2006;20:870-6.

43 Thevis $M$, Schänzer W. Mass spectrometry of selective androgen receptor modulators. J Mass Spectrom 2008:43:865-76.

44 Thevis M, Piper T, Beuck S, et al. Expanding sports drug testing assays: mass spectrometric characterization of the selective androgen receptor modulator drug candidates RAD140 and ACP-105. Rapid Commun Mass Spectrom 2013;27:1173-82.

45 Thevis M, Gerace E, Thomas A, et al. Characterization of in vitro generated metabolites of the selective androgen receptor modulators $\mathrm{S}-22$ and $\mathrm{S}-23$ and in vivo comparison to post-administration canine urine specimens. Drug Test Anal 2010;2:589-98

46 Thevis $\mathrm{M}$, Geyer $\mathrm{H}$, Kamber $\mathrm{M}$, et al. Detection of the arylpropionamide-derived selective androgen receptor modulator (SARM) S-4 (Andarine) in a black-market product. Drug Test Anal 2009;1:387-92.

47 Thevis M, Geyer $\mathrm{H}$, Thomas A, et al. Trafficking of drug candidates relevant for sports drug testing: detection of non-approved therapeutics categorized as anabolic and gene doping agents in products distributed via the Internet. Drug Test Anal 2011:3:331-6. 
48 Grata E, Perrenoud L, Saugy M, et al. SARM-S4 and metabolites detection in sports drug testing: a case report. Forensic Sci Int 2011;213:104-8.

49 Starcevic B, Ahrens BD, Butch AW. Detection of the selective androgen receptor modulator S-4 (Andarine) in a doping control sample. Drug Test Anal 2013:5:377-9.

50 Geyer H, Braun H, Burke LM, et al. Inadvertent doping. In: A-Z of nutritional supplements: dietary supplements, sports nutrition foods and ergogenic aids for health and performance-part 22. Br J Sports Med 2011;45:752-4.

51 Vernec A, Stear SJ, Burke LM, et al. A-Z of nutritional supplements: dietary supplements, sports nutrition foods and ergogenic aids for health and performance: part 48. Br J Sports Med 2013;47:998-1000.

52 Guddat S, Fusshöller G, Geyer H, et al. Clenbuterol—regional food contamination a possible source for inadvertent doping in sports. Drug Test Anal 2012:4:534-8

53 Thevis M, Geyer L, Geyer H, et al. Adverse analytical findings with clenbuterol among U-17 soccer players attributed to food contamination issues. Drug Test Anal 2013;5:372-6

54 Nicoli R, Petrou M, Badoud F, et al. Quantification of clenbuterol at trace level in human urine by ultra-high pressure liquid chromatography-tandem mass spectrometry. J Chromatogr A 2013;1292:142-50.
55 Thevis $\mathrm{M}$, Thomas $\mathrm{A}$, Beuck $\mathrm{S}$, et al. Does the analysis of the enantiomeric composition of clenbuterol in human urine enable the differentiation of illicit clenbuterol administration from food contamination in sports drug testing? Rapid Commun Mass Spectrom 2013;27:507-12.

56 Segura J. Is anti-doping analysis so far from clinical, legal or forensic targets?: The added value of close relationships between related disciplines. Drug Test Anal 2009;1:479-84.

57 Thevis M, Fusshöller G, Schänzer W. Zeranol: doping offence or mycotoxin? A case-related study. Drug Test Anal 2011;3:777-83.

58 Thevis M, Schänzer W, Geyer H, et al. Traditional Chinese medicine and sports drug testing: identification of natural steroid administration in doping control urine samples resulting from musk (pod) extracts. Br J Sports Med 2013;47:109-14.

59 Schänzer W, Geyer H, Fusshöller G, et al. Mass spectrometric identification and characterization of a new long-term metabolite of metandienone in human urine. Rapid Comm Mass Spectrom 2006;20:2252-8.

60 Gomez C, Pozo OJ, Garrostas L, et al. A new sulphate metabolite as a long-term marker of metandienone misuse. Steroids 2013;78:1245-53.

61 Guddat S, Fusshöller G, Beuck S, et al. Synthesis, characterization, and detection of new oxandrolone metabolites as long-term markers in sports drug testing. Anal Bioanal Chem 2013;405:8285-94. 